\title{
Generation of Synthetic Daily Weather for Climate Change Scenarios and Extreme Storm Intensification
}

\author{
Jurgen Garbrecht ${ }^{1}$, X. C. (John) Zhang ${ }^{1}$, David Brown ${ }^{1} \&$ Phillip Busteed $^{1}$ \\ ${ }^{1}$ Grazinglands Research Laboratory, US Dept. of Agriculture, Agricultural Research Service, El Reno, Oklahoma, \\ USA
}

Correspondence: Jurgen Garbrecht, Grazinglands Research Laboratory, US Dept. of Agriculture, Agricultural Research Service, 7207 Cheyenne Street, El Reno, Oklahoma, USA. Tel: 405-262-5291. E-mail: Jurgen.Garbrecht@ars.usda.gov

Received: February 22, 2019

Accepted: March 15, 2019 Online Published: March 20, 2019

doi:10.5539/enrr.v9n2p1

URL: https://doi.org/10.5539/enrr.v9n2p1

\begin{abstract}
Long-term simulations in watershed hydrology, soil and nutrient transport, and sustainability of agricultural production systems require long-term weather records that are often not available at the location of interest. Generation of synthetic daily weather data is a common approach to augment limited weather observations. Here a synthetic daily weather generation model (called SYNTOR) is described. SYNTOR fulfills the traditional role of generating alternative weather realizations that have statistical properties similar to those of the parent historical weather it is intended to simulate. In addition, it has the capability to simulate daily weather records for climate change scenarios and storm intensification due to climate change. The various model components are briefly summarized and an application is presented for semi-arid climate conditions in west-central Oklahoma. SYNTOR generated daily weather compared well with observed weather values. Climate change is simulated by adjusting weather generation parameters to reflect the changed mean monthly weather values of climate projections. Storm intensification is approximated by increasing the top 10 percentile of storm distribution by a predefined amount based on previous studies of trends in United States precipitation. Further evaluation of published storm intensification values and associated uncertainties and spatial variability is recommended.
\end{abstract}

Keywords: Climate Change, Storm Intensity, Synthetic Weather, Weather Generator

\section{Introduction}

The professional literature reports on an unambiguous upward trend in the frequency of heavy to extreme storms in regions of the United States (Kunkel et al., 2003; IPCC, 2013). This increase is linked closely to rising global temperatures. For example, IPCC-AR5 (2013) reported that the 20-year return storms of the late $20^{\text {th }}$ century would have a nearly 15 -year return period by 2100 , concomitant with a $1^{\circ} \mathrm{C}$ temperature rise in large parts of North America. The intensification of heavy to extreme storm events is expected to continue, and to disrupt the environment by creating more frequent and severe flooding episodes.

Observed daily precipitation, air temperature, and solar radiation, herein referred to as weather, are frequently incorporated into agricultural and environmental computer models to investigate sustainability of agricultural production systems. These investigations include the effectiveness of soil and water conservation practices, hydrologic response of watersheds, and provisions of decision support information for crop management (Zhang, 2007; Soltani \& Hoogenboom, 2003; Baigorria et al., 2008; Meinke et al., 2007). Extreme storm intensification is particularly relevant for flash-flood protection, soil erosion control, and downstream sedimentation because these detrimental effects increase exponentially with storm intensity (Garbrecht et al., 2014; Nearing et al., 2005).

Investigations of climate change and its impacts on agriculture and the environment depend on using complex computer models, which require large volumes of climatic and physiographic data that are often not available on an in-situ basis or for a long period of record. In order to best assess potential changes in weather type, frequencies, and intensities in a changing climate, alternative synthetic weather realizations are needed to enable the analysis of a range of potential responses and impacts, thereby capturing the uncertainty associated with applications that depend on the stochastic nature of weather. 
A common mathematical-statistical approach to augment observed weather data consists of generating alternative weather realizations that have statistical properties similar to those of the parent historical weather. However, generating alternatives of the same historical weather patterns limits model applications to issues related to or dependent upon historical weather observations. A wealth of new application opportunities would arise if one were to generate daily weather for climate change scenarios and storm intensification due to climate change (Wilks \& Murphy, 1985, 1986; Garbrecht et al., 2010). A weather generator with the above capabilities would be expected to reproduce the number of rainy days, daily precipitation amounts, sequencing of wet and dry days, frequency of extreme storm events, daily air temperature, and solar radiation in a manner consistent and compatible with historical and local climate characteristics.

The objective of this study is to develop and test enhancements to a point weather generator model, SYNTOR (SYNthetic weather generaTOR), to include weather generation capabilities for climate change and intensification of extreme storm events. Limitations and relevant assumptions related to the model and its generation of synthetic weather are reviewed, and the performance of the implemented enhancements is demonstrated via a climate change application for the semi-arid conditions of west-central Oklahoma. The successful demonstration of a weather generator model with these enhancements could be used to inform and improve risk tolerance and decision-making for production agriculture and numerous other applications requiring design storm under changing climatic conditions.

\section{Materials and Methods}

SYNTOR is not a predictor of future climate conditions, but rather generates daily weather for user-selected future climate scenarios. The model requires a complete record of observed daily weather data on the order of 20 to 30 years with no missing values to derive site-specific regression coefficients, distribution parameters, and relationships needed to generate daily weather realizations. The generation of synthetic daily weather by SYNTOR consists of first identifying rainy and rain-free days, followed by the determination of the amount of precipitation on rainy days. Daily minimum and maximum air temperature and solar radiation are treated in an integrated fashion to preserve the serial and cross correlation between these weather variables. The strong dependence of air temperature and solar radiation on rainy and rain-free days is accounted for by using two sets of coefficients in the model, one for rainy days and another for rain-free days. Likewise, the nonstationary variations in climate and weather within a year due to seasons is introduced by using separate weather generation parameters for each calendar month (Wilks, 1989). Once the daily precipitation, air temperature, and solar radiation are determined, the intensification of extreme storms due to climate change is calculated. The generation of synthetic daily precipitation was previously investigated (Garbrecht \& Zhang, 2014) and is only summarized here as needed for clarity and sake of completeness. The focus of this study is on the model enhancements that enabled generation of synthetic weather for climate change scenarios and storm intensification due to climate change.

\subsection{Daily Precipitation Model}

\subsubsection{Generation of Observed Daily Precipitation}

Two sequential steps are needed to generate daily precipitation: first, occurrence of a rainy day, and second, amount of precipitation on rainy days (Waymire \& Gupta, 1981). Occurrence of rainy days is determined by a two-state, first-order Markov chain. The Markov chain is said to be two-state because it only considers whether precipitation does or does not occur on a specific day, and it is first-order because the probability of precipitation on a rainy day depends only on the precipitation state of the previous day. The probabilities of precipitation given the previous day's precipitation state are called transition probabilities. The transition probabilities considered here are the probability of a wet day after a dry day (PWD), and of a wet day after a wet day (PWW). Available historical daily precipitation data are used to determine the transition probabilities for each calendar month (Wilks, 1989).

Precipitation amount on a rainy day is determined by random sampling from a cumulative probability distribution function of daily precipitation amounts. Richardson (1982) investigated three distributions of daily precipitation amount (one-parameter exponential, two-parameter gamma, and three-parameter mixed exponential) and concluded that the mixed (double) exponential distribution performed best. Hence, the double exponential distribution was selected for use in this study. Synthetic daily precipitation values were determined by drawing a random number from a uniform distribution between 0 and 1 , and using this random number as the probability-of-exceedance (POE) value for which the corresponding daily precipitation amount is sought. This process was repeated until the generated record of synthetic daily precipitation reached the desired length. Seasonality in precipitation was introduced by using different daily precipitation distributions for each calendar 
month. Parameters of the daily precipitation distribution (the double exponential distribution) were derived from the available historical daily precipitation.

\subsubsection{Generation of Daily Precipitation for Climate Change Scenarios}

Climate change is defined as a permanent departure in average monthly weather from climatology. The long-term nature of climate change investigations lends itself more readily to strategic planning rather than tactical decision-making. Climate change projections, simulated by Global Circulation Models (GCM), are available from a number of sources (e.g., Reclamation, 2013; IPCC, 2013).

Departures in monthly precipitation amounts due to a climate change lead to direct changes in average number of rainy days, average rainy day amount, and transition probabilities of PWD and PWW. These changes necessitate the recalculation of the precipitation generation parameters to ensure that generated precipitation amounts accurately reproduce the monthly statistics that were used to quantify the climate change. Changes in these variables are estimated based on regression relationships derived from historical daily precipitation data. The relation that partitions the increased precipitation into number of rainy days and amount of precipitation on rainy days was reported in Garbrecht and Zhang (2014).

The lead-time for climate change investigations often exceeds one, two, or more decades in order to allow the gradual climate change to become discernable above the year-to-year climate variability of GCM monthly projections. The long lead-time allows the gradual change in climate to accumulate and provide the basis for SYNTOR to generate daily weather representative of future climatic conditions. However, it is noted that as the lead time of the climate projection increases so does the uncertainty of the projection.

\subsection{Daily Temperature and Solar Radiation Model}

\subsubsection{Generation of Daily Minimum and Maximum Air Temperature and Solar Radiation}

Daily minimum (Tmin) and maximum (Tmax) air temperatures and solar radiation are modeled as continuous processes that are conditioned on the occurrence of a rainy or rain-free day. Historic daily air temperature data must be given as daily minimum and maximum air temperature. SYNTOR will calculate each variable's relationship to precipitation (i.e. mean and standard deviation) separately in order to generate daily minimum and maximum air temperature for rainy and rain-free days. Temperature and solar radiation are assumed to be normally distributed with a mean and standard deviation calculated from observed historical weather data. The weather variables are dependent on one another (cross correlation) and are persistent in time (serial correlation). All generated temperature and solar radiation are calculated and provided on a calendar month basis to accurately model seasonality in air temperature and solar radiation.

The residuals of Tmin, Tmax, and solar radiation are generated using a multi-variate normal generation procedure that preserves the serial correlation and cross correlation coefficients of the variables. The procedure is based on the weakly stationary generating process. A detailed description of matrices and matrix transformations are further provided in Richardson and Wright (1984).

Generation of daily Tmin, Tmax, and solar radiation consists of multiplying the generated residuals by the standard deviation and adding a seasonal mean to the generated residuals (Richardson, 1985). To account for rainy and rain-free days, a different mean and standard deviation are applied to wet and dry days in the observed historical record (Richardson, 2000). Seasonal changes in Tmin, Tmax, and solar radiation are modeled by calculating the weather variables on a calendar month basis.

Implementation of the air temperature and solar radiation models necessitates that generated Tmin and Tmax be within a range of +50 and -50 degrees Celsius. The intent of this temperature range is to catch potential outliers from possible data entry error or typos. The value of $\pm 50^{\circ} \mathrm{C}$ was obtained by reviewing extreme daily temperature value in the continental US.

Solar radiation at ground level is restricted to be within 0.05 and 0.85 . The value of 0.05 is near complete darkness, and the value of 0.85 is the maximum possible on a super clear day. Finally, conservation of energy is enforced by spreading any difference between generated air temperature and corresponding observed historical temperature (approximation error) evenly over all generated daily air temperature values.

\subsubsection{Generation of Daily Tmin, Tmax, and Solar Radiation for Climate Change Scenarios}

SYNTOR uses either average air temperature or minimum and maximum air temperature for climate change. If average air temperature is used, then the model uses the regressions between minimum, maximum, and average air temperature of the historic daily data to generate minimum and maximum air temperature of the climate change based on changes to only average air temperature. Temperature values of a climate change are modeled 
as a shift in the distribution of historical daily air temperatures. The size of the shift is the difference in air temperature between the mean of the climate change and mean historical temperature distributions. The maximum allowable calendar month mean shift due to climate change is plus or minus 8 degrees Celsius. This maximum departure amount was based subjectively on the published results from various Global Circulation Models (GCM) for Representative Concentration Pathway (RCP) 8.5 by the year 2100 (IPCC, 2013 and 2014). The updated air temperature is used to recalculate the statistics of daily Tavg, Tmin, and Tmax which, in turn, are used by SYNTOR to generate synthetic daily air temperature for the climate change. All seasonal temperature calculations are performed on a calendar month basis.

Biases and approximation errors are minimized by enforcing the principle of energy conservation between generated and user-specified projected air temperature, i.e., no gain or loss of energy in the system. Any difference in total energy is attributed to limitation or bias of the simulation model, and the approximation error is spread evenly over all generated daily air temperature values. Thus, a hypothetical difference of $0.1{ }^{\circ} \mathrm{C}$ in total energy is corrected by adding $0.1^{\circ} \mathrm{C}$ to all generated daily temperature values. This is performed on a calendar month basis.

Climate change for solar radiation are not commonly issued in output datasets. Thus, daily solar radiation in SYNTOR is governed by changes in the wet and dry condition of the day, changing inclination of the planet with day of the year, and cross correlation with air temperature. These cause-effect relationships that govern solar radiation are included in SYNTOR.

\subsection{Intensification of Extreme Storm Events}

\subsubsection{Considerations}

The term "intensification" implies something is increasing. By extension, extreme storm intensification means that daily precipitation amount in the category of "extreme storms" is increasing, or alternatively the number of extreme storm events in that category is increasing. In SYNTOR this intensification in precipitation due to climate change is modeled in a post-processing step that adjusts the intensity of extreme storm events by a user pre-specified precipitation amount reflecting the intensification. The intensification model is empirical, flexible and can accommodate a large range of storm intensities. The precipitation adjustment for intensification is user specified for each of the five percentile categories given in Table 1 (Joshi et al., 2019) The size of the adjustment is restricted by design to be within $-10 \%$ and $+60 \%$.

Table 1. Percentile ranges of the upper 90 percentiles of precipitation, the corresponding precipitation ranges, and classification by frequency of occurrence. Weather station at Weatherford, Oklahoma

\begin{tabular}{llll}
\hline & Percentile Categories & Precip. Ranges at Weatherford, OK & Frequency of occurrence \\
\hline Intense rain & $90-95 \%$ & 30.0 to $42.8 \mathrm{~mm}$ & No more than 5 out of 100 \\
Very Intense rain & $95-99 \%$ & 42.8 to $77.1 \mathrm{~mm}$ & No more than 4 out of 100 \\
Heavy rain & $99-99.7 \%$ & 77.2 to $105.1 \mathrm{~mm}$ & No more than 1 out of 100 \\
Very heavy rain & $99.7-99.9 \%$ & 106.7 to $129.9 \mathrm{~mm}$ & No more than 2 out of 1000 \\
Extreme rain & 99.9 and above & 130.1 to $242.7 \mathrm{~mm}$ & No more than 1 out of 1000 \\
\hline
\end{tabular}

One consequence of specifying the increase in daily precipitation needed to produce a desired intensification is a net gain of total precipitation from its initial value without intensification. Two options are available to address this concern. First option, the increase in daily precipitation in the $95-100$ percentile category is balanced by a precipitation reduction of equal amount over all precipitation events. The intensification model does not gain or lose precipitation. Second option, the model accepts the increase in precipitation due to intensification. Precipitation mass balance is not assured and net precipitation may be gained or lost.

Groisman et al. (2005) reported that the characteristics of very heavy and extreme precipitation should be averaged over large, spatially homogeneous regions in order to obtain statistically significant estimates of storm intensification. High frequency (short-term) information in the weather data at small spatial scales masks lower frequency (long-term) change, and makes it difficult to detect precipitation intensification over time. This was confirmed by the authors' attempt to detect a trend in the 1949-2017 daily precipitation record for Weatherford, Oklahoma. Thus, area-averaged precipitation over a large homogeneous region seems to be a pre-requisite to uncover and simulate the intensification of very heavy to extreme precipitation events (Groisman et al., 2005).

Fortunately, trends in heavy, very heavy, and/or extreme precipitation in the United States have been investigated 
and estimates of intensification can be inferred from existing data in the published literature. Most notable is the work by Groisman et al. $(2001,2005)$ and Kunkel et al. $(1999,2003)$. Groisman et al. (2005) reported that area-averaged rainfall characteristics over large regions (Upper Mississippi, South, Midwest) showed statistically significant annual increases in very heavy and extreme precipitation for the 1908-2002 time-period. In regard to the Great Plains region, the increase in the amount of precipitation falling in very heavy events (defined as the heaviest $1 \%$ of all daily events) from 1958-2012 was about $16 \%$ (Karl et al., 2009). In the eastern third of the United States, the change in very heavy precipitation ranged from $27 \%$ to $71 \%$, while in the Southwest, the trends were not larger than natural variations (Walsh et al., 2014).

\subsubsection{Generation of Daily Intensification of Extreme Precipitation Events}

First, the initial generated time-series of daily precipitation (all rainy days) is sorted by volume from high to low and categorized or ranked based on their probability of non-exceedance (percentile or percentile rank). The ranking of the daily data into percentiles allow the easy identification of those extreme daily precipitation events that belong to one of the five categories given in Table 1 . The identified daily precipitation values that fall within one of the five percentile categories are then increased by a user-specified percentage or percent change. This step is repeated until the five precipitation categories are complete, and the corresponding daily precipitation values are increased by the user-provided percentages due to intensification. This interim result is the intensified daily precipitation distribution.

Next, the intensified daily precipitation distribution is reverse-sorted into a time-series having exactly the same rainy-day sequence as the original generated time-series before intensification. The only difference is the change in daily precipitation due to intensification of extreme storm events in the five percentile categories. Finally, the impact that changes in daily precipitation on total monthly precipitation is considered. If the intention is to preserve mass balance of water (first intensification option), then the difference between non-intensified and intensified daily precipitation is calculated for each calendar month, and the difference is distributed proportionally over all daily precipitation values of that calendar month. This is done for each calendar month separately, resulting in a zero-sum monthly and annual precipitation budget. This ensures that the simulation of precipitation intensification closely approximates the GCM provided calendar month monthly precipitation.

\subsection{Generation of Synthetic Weather for a Semi-Arid Climate in West-Central Oklahoma}

Generation of synthetic weather information using SYNTOR is well-illustrated by a proof-of-concept example, particularly to highlight the model enhancements related to climate change scenarios and extreme storm intensification. In this example, selected synthetic daily precipitation and temperature generated by SYNTOR are compared to observed weather at the town of Weatherford in west-central Oklahoma in the Great Plains region of the United States. Weatherford was selected as the location of the application because a serially complete, 38-year record (1980-2017) of high quality daily precipitation and air temperature observations was available.

\subsubsection{Generation of Synthetic Precipitation for Baseline Climatic Conditions}

Table 2. Mean and standard deviation of generated (200 years) and observed (38 years) annual and daily precipitation (above $0.5 \mathrm{~mm}$ ), and annual mean min. and mean max. air temperature at Weatherford, OK. (All precipitation values are in $\mathrm{mm}$ and temperature values in ${ }^{\circ} \mathrm{C}$ )

\begin{tabular}{|c|c|c|c|c|c|}
\hline & & Mean & St. Dev. & Minimum & Maximum \\
\hline \multicolumn{6}{|l|}{ Annual precipitation } \\
\hline & Observed & 760 & 184 & 416 & 1269 \\
\hline & Generated & 760 & 154 & 268 & 1208 \\
\hline \multicolumn{6}{|l|}{ Daily precipitation } \\
\hline & Observed & 11.9 & 15.9 & 0.5 & 168 \\
\hline & Generated & 12.0 & 15.5 & 0.5 & 210 \\
\hline \multicolumn{6}{|l|}{ Annual mean of max. temperature } \\
\hline & Observed & 22.3 & 0.82 & 20.6 & 24.4 \\
\hline & Generated & 22.3 & 0.70 & 20.3 & 24.2 \\
\hline \multicolumn{6}{|l|}{ Annual mean of min. temperature } \\
\hline & Observed & 9.0 & 0.59 & 8.0 & 10.1 \\
\hline & Generated & 9.0 & 0.57 & 7.4 & 10.6 \\
\hline
\end{tabular}


Basic statistics and probability-of-exceedance (POE) curves of generated daily, monthly, and annual precipitation are shown in Figures 1-6 and Table 2. Plots of observed and generated daily and annual precipitation show good correspondence, as do most of the related statistics (Table 2). One likely reason for this good fit is the enforcement of conservation of precipitation water. Any discrepancy between generated and observed precipitation was re-distributed proportionally to the daily precipitation amount over all generated daily precipitation events. The POE plot of annual maximum daily precipitation shows a fair correspondence with that of the observed data (Figure 4). This is also true for the POE plot of calendar month precipitation based on observed historical (1980-2017) and SYNTOR generated (200 years) daily precipitation (Figure 6).

The difference in distributions between generated and observed annual and monthly precipitation were tested for statistical significance (Wilcoxon-Mann-Whitney and Welch's $\mathrm{T}$ tests). Differences were not statistically significant (Figures 1, 2, 4, 5, and 6). Therefore, the generated monthly precipitation was considered to be a faithful representation of the observed precipitation.

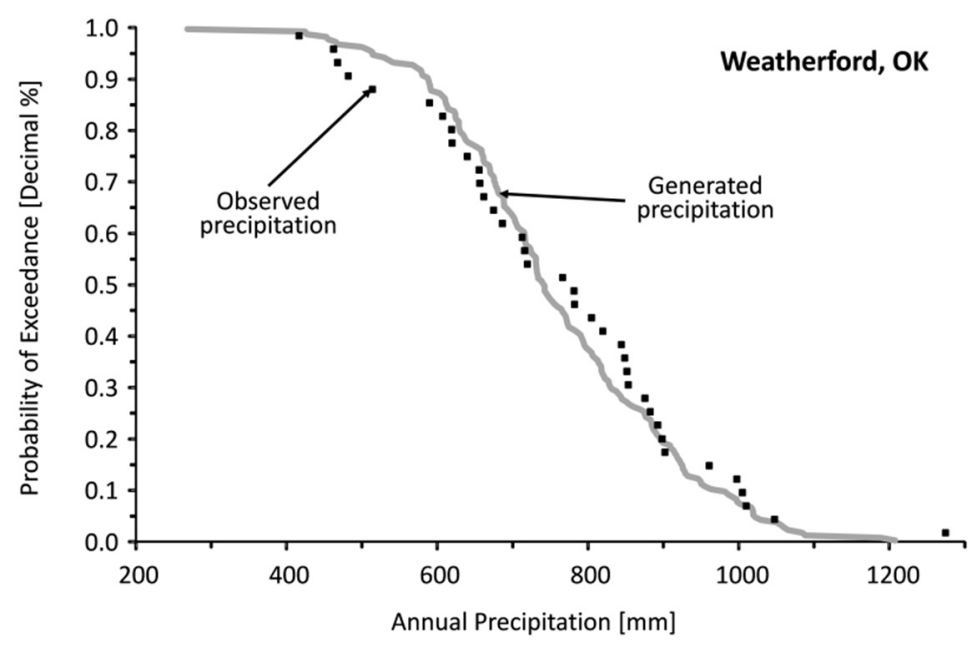

Figure 1. Probability-of-Exceedance of annual precipitation derived from observed historical (1980-2017) and SYNTOR generated (200 years) daily precipitation at Weatherford, OK.

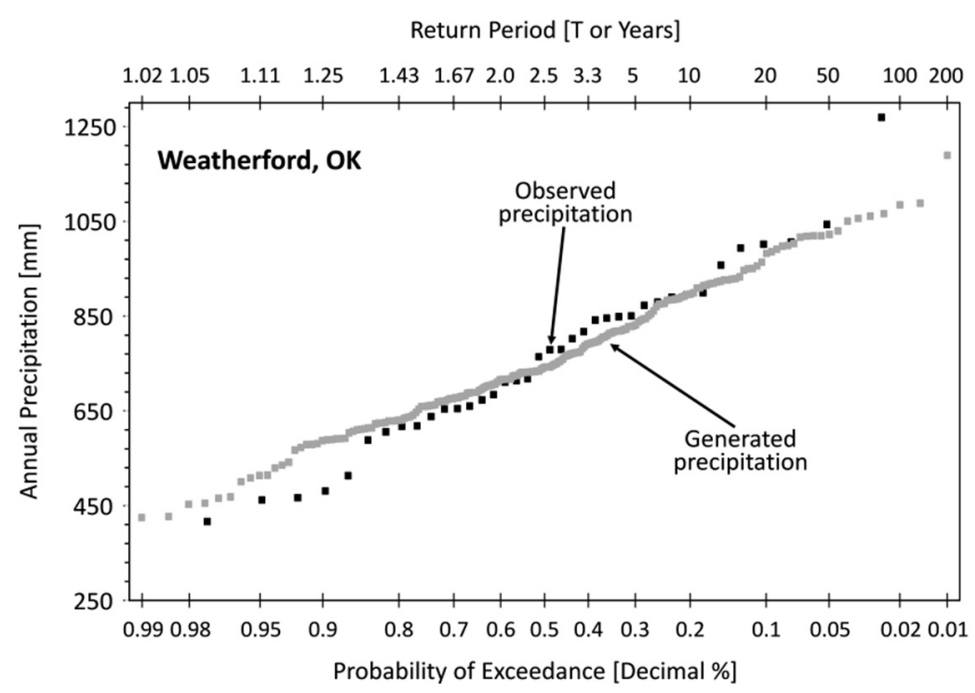

Figure 2. Annual precipitation frequency derived from observed historical (1980-2017) and SYNTOR generated (200 years) daily precipitation at Weatherford, OK. 


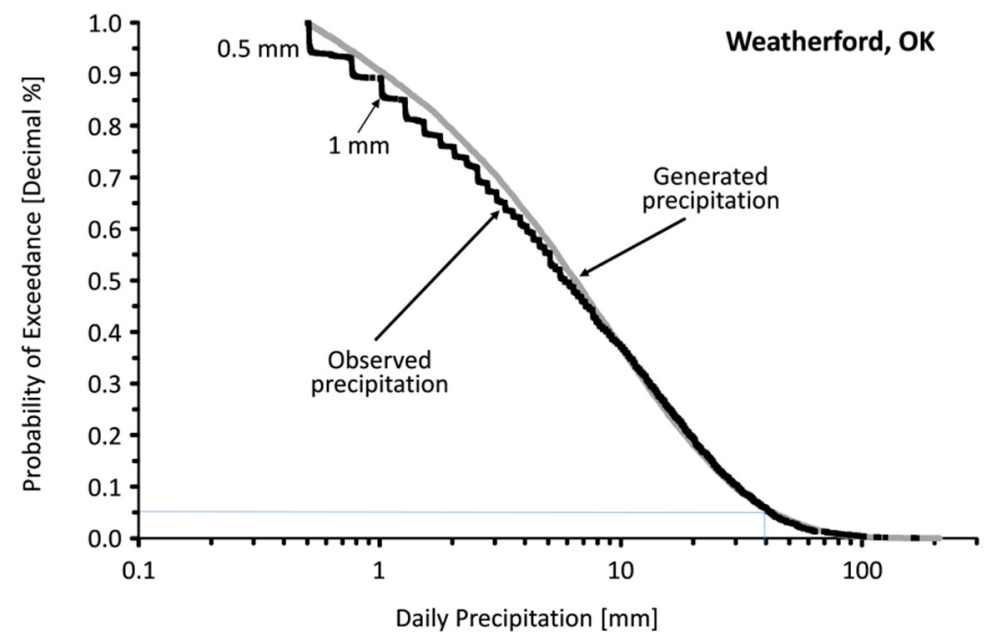

Figure 3. Probability-of-Exceedance of daily precipitation of observed historical (1980-2017) and SYNTOR generated (200 years) daily precipitation at Weatherford, OK.

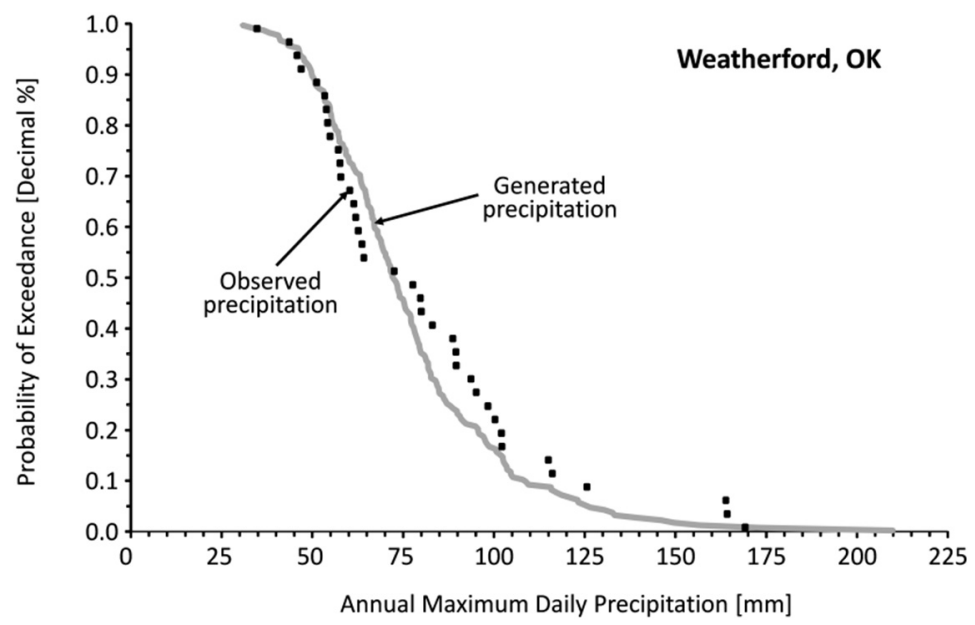

Figure 4. Probability-of-Exceedance of annual max daily precipitation based on observed historical (1980-2017) and SYNTOR generated (200 years) daily precipitation at Weatherford, OK.

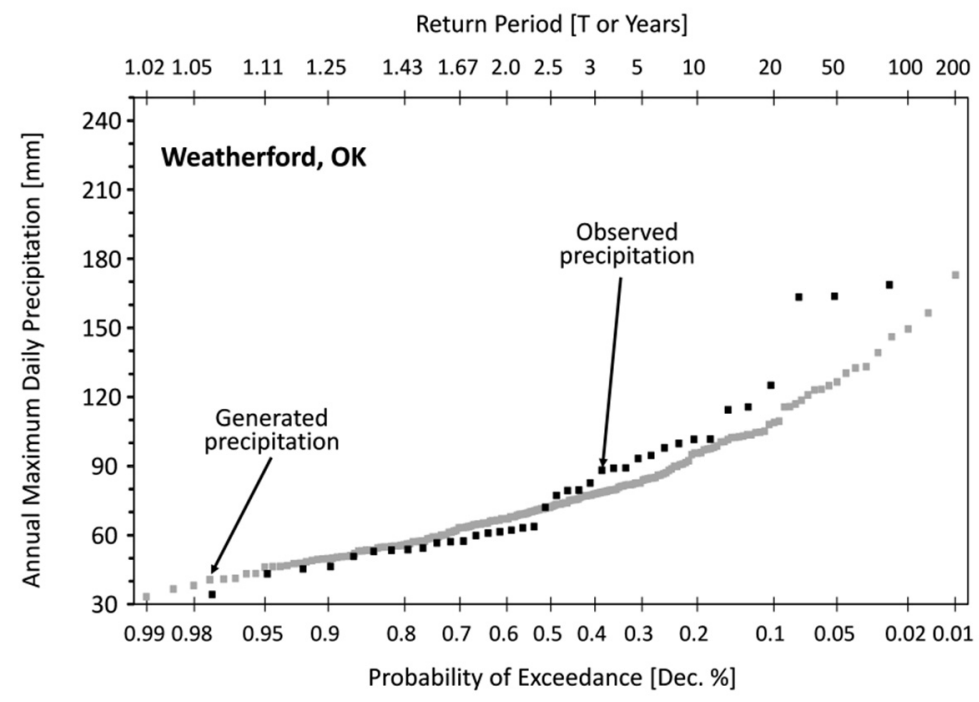

Figure 5. Frequency of annual max daily precipitation derived from observed historical (1980-2017) and SYNTOR generated (200 years) daily precipitation at Weatherford, OK. 

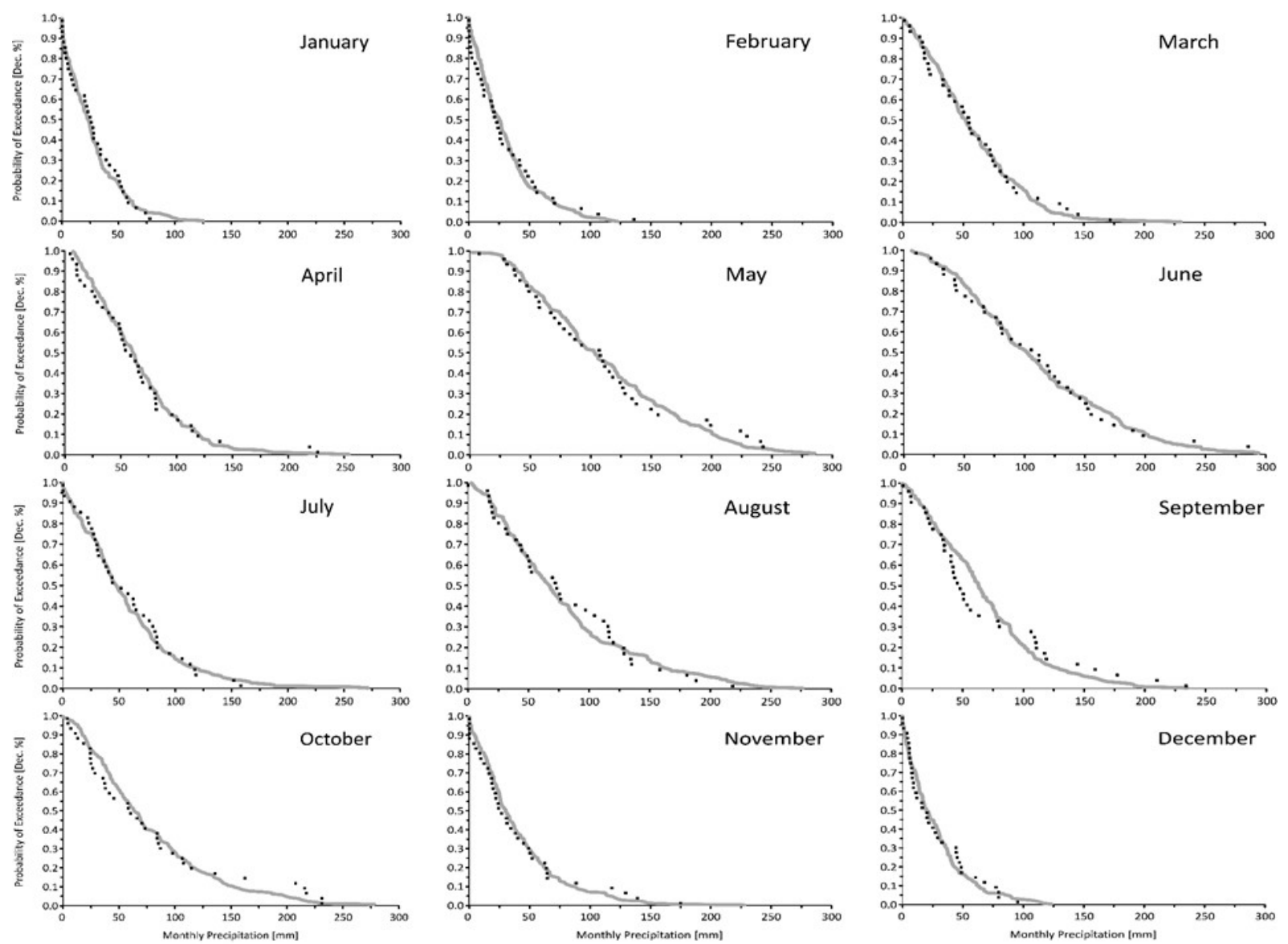

Figure 6. Probability-of-Exceedance of mean monthly precipitation by calendar month based on observed historical (1980-2017) and SYNTOR generated (200 years) daily precipitation at Weatherford, OK.

\subsubsection{Generation of Synthetic Air Temperature for Baseline Climatic Conditions}

POE curves for annual and daily Tmin and Tmax are shown in Figures 7, 8, 10, and 11. The basic statistics are provided in Table 3. The observed and SYNTOR-generated daily Tmin and Tmax POE graphs are given in Figures 8, 9, and 11. Both the Wilcoxon-Mann-Whitney test and Welch's T test cannot reject, at an alpha level of 0.05 , the contention that the generated and observed annual, monthly, and daily max Tmin and Tmax come from the same population. All calendar month graphs of monthly Tmin and Tmax distributions show that the SYNTOR-generated monthly temperature track observed temperatures (Figure 9).

Table 3. Mean and standard deviation of generated climate change with storm intensification (200 years) and CCSM4 projected (30 years) 2041-2070 annual precipitation, and annual mean min. and mean max. air temperature at Weatherford, OK.

\begin{tabular}{|c|c|c|c|c|c|}
\hline & & Mean & St. Dev. & Minimum & Maximum \\
\hline \multicolumn{6}{|l|}{ Annual precipitation } \\
\hline & CCSM4 & 807.5 & 197.5 & 402.5 & 1157.2 \\
\hline & Generated & 819.1 & 168.2 & 412.4 & 1445.7 \\
\hline \multicolumn{6}{|l|}{ Annual mean of max. temperature } \\
\hline & CCSM4 & 24.4 & 1.0 & 22.5 & 26.1 \\
\hline & Generated & 24.4 & 0.7 & 22.4 & 26.3 \\
\hline \multicolumn{6}{|l|}{ Annual mean of min. temperature } \\
\hline & CCSM4 & 11.2 & 0.9 & 9.8 & 13.6 \\
\hline & Generated & 11.2 & 0.6 & 9.6 & 12.9 \\
\hline
\end{tabular}




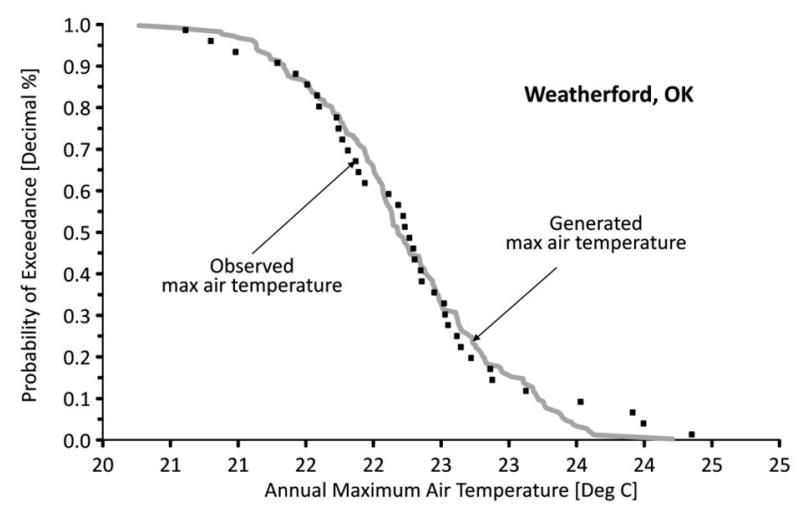

Figure 7. Probability-of-Exceedance of annual max air temperature derived from observed historical (1980-2017) and SYNTOR generated (200 years) daily temperature at Weatherford, OK

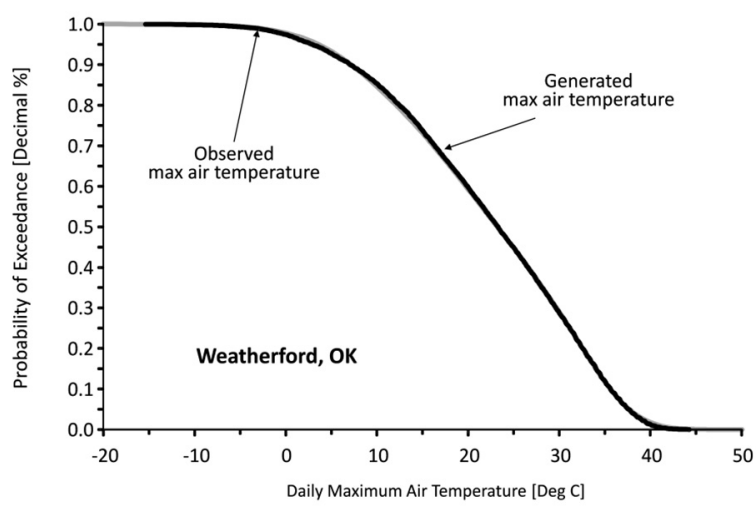

Figure 8. Probability-of-Exceedance of daily max temperature of observed historical (1980-2017) and

SYNTOR generated (200 years) daily max temperature at Weatherford, OK
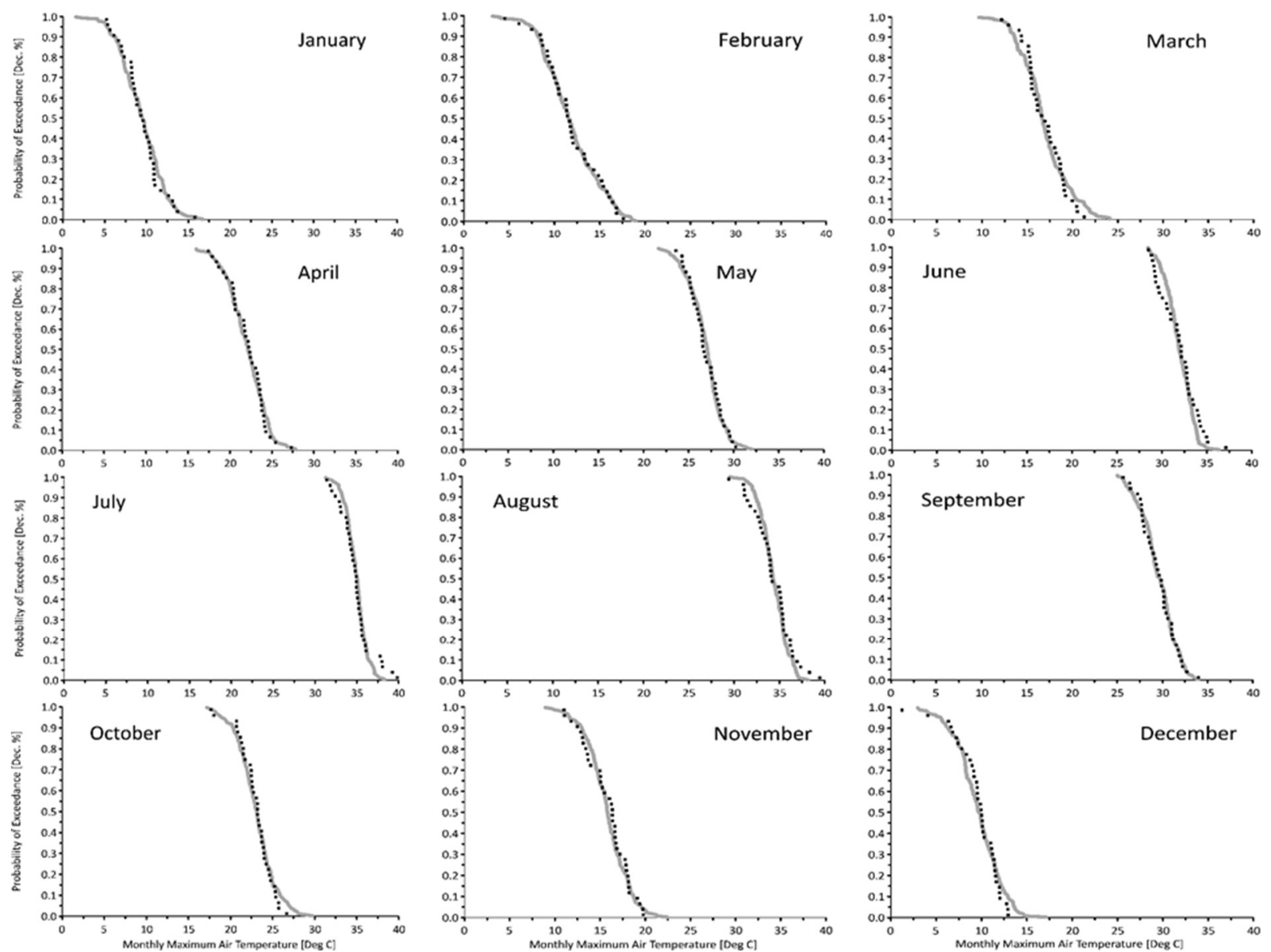

Figure 9. Probability-of-Exceedance of mean monthly max air temperature by calendar month based on observed historical (1980-2017) and SYNTOR generated (200 years) daily max temperature at Weatherford, OK 


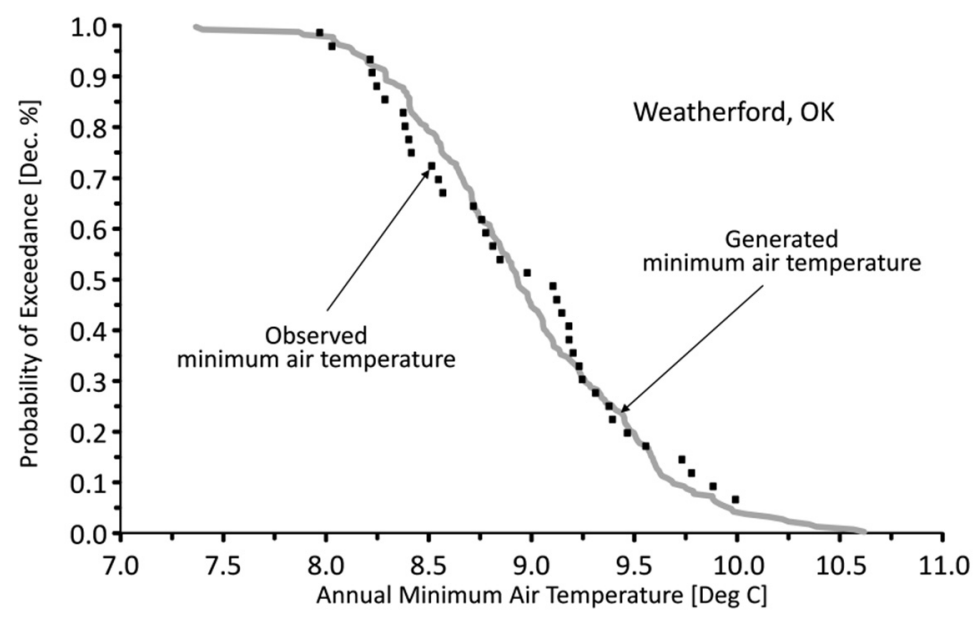

Figure 10. Probability-of-Exceedance of annual min air temperature derived from observed historical (1980-2017) and SYNTOR generated (123 years) daily temperature at Weatherford, OK.

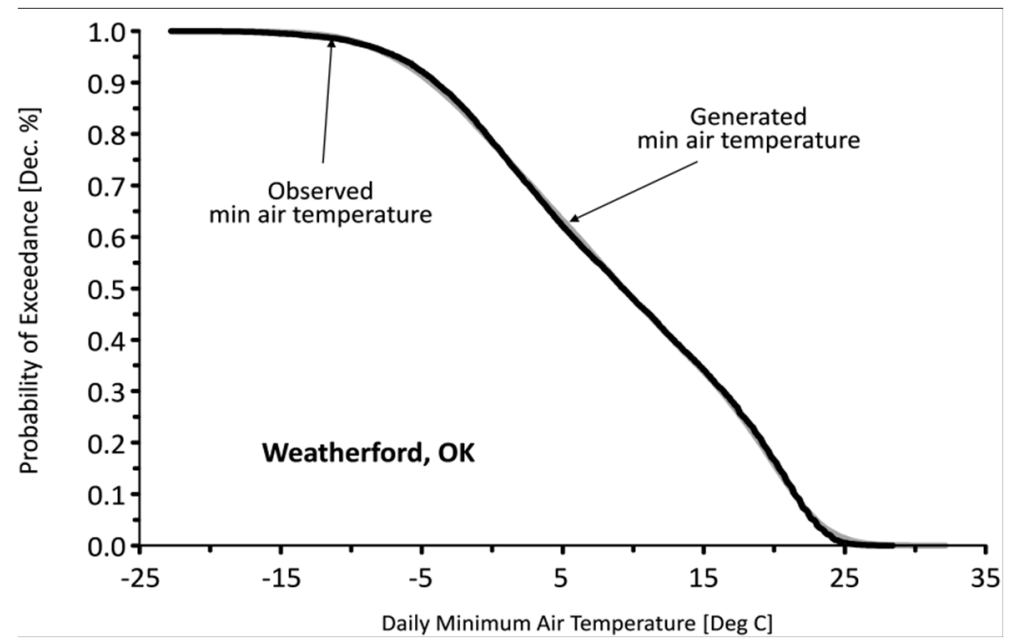

Figure 11. Probability-of-Exceedance of daily min air temperature of observed historical (1980-2017) and SYNTOR generated (200 years) daily min temperature at Weatherford, OK.

\subsubsection{Generation of Synthetic Weather for a Climate Change Scenario}

The climate change projection used is the General Circulation Model (GCM) "CCSM4", developed by the National Center of Atmospheric Research (NCAR) at Boulder, Colorado. The greenhouse gas (GHG) emission scenario selected for evaluation was the Representative Concentration Pathway 8.5 (RCP 8.5). In RCP 8.5, emissions continue to rise throughout the 21 st century (IPCC, 2013). The precipitation and air temperature projections driven by CCSM4 are available at a downscaled grid size of $12 \times 12 \mathrm{~km}$ and at monthly time increments (Reclamation, 2013). The grid location selected for this study encompassed the town of Weatherford, Oklahoma. The 30-year time period of the analyzed projection was 2041 to 2070. The calendar month means were summarized for Tmin, Tmax, and Precipitation and entered into SYNTOR to generate 200 repeat-years of synthetic weather at Weatherford and representative of the 2041-2070 time period.

The traditional approach to determine the performance of a model is by comparison with observational data. In this case, the future climate cannot be observed. Instead, the following considerations must be addressed to determine if SYNTOR adequately models daily weather under a given climate change scenario. First, the choice of a GHG emission scenario and climate projection model (GCM) determines the climate change pattern. SYNTOR only downscales the provided climate change pattern to daily and local (field) scales based on the statistical properties of the parent historical weather. Second, the evolution in time of the climate change is 
determined by the selected GCM. SYNTOR assumes steady state conditions and generates projected daily weather based on calendar month means of the GCM for a particular future time period. Third, differences in projected climate change by different GCMs determines the uncertainty of the projected path of climate change.

None of the above three climate change patterns are simulated by SYNTOR. Rather, SYNTOR relies on the characteristics of the selected climate change scenario and historical weather, the length of the projection time period, and the projected mean monthly precipitation and air temperature to generate daily weather consistent with the scenario, climate model, projection time period, and location of interest. Based upon these considerations, the annual statistics of the generated daily weather of the 2041-2070 time period are compared to those of the CCSM4 projection (Table 3). The plots and basic statistics of projected and generated monthly and annual precipitation and air temperature are shown in Figures 12-16 and Table 3. The results of the SYNTOR-generated weather closely match the monthly and annual values of the CCSM4 model. This is expected because SYNTOR uses the mean monthly projections of the GCM model to compute the daily weather values.

The annual and monthly plots of SYNTOR-generated and CCSM4 weather appear to be very similar in size and distribution. As a result, the SYNTOR generated weather is considered representative of CCSM4 projected weather for the given climate change scenario. However, the SYNTOR-generated annual precipitation in Figure 12 displays a reduced spread compared to that of the spatially down scaled CCSM4 annual precipitation values. This is the case for many weather generators (Zhang \& Garbrecht, 2003), simply because precipitation dependencies of month-to-month and year-to-year (persistence effect) are not considered.

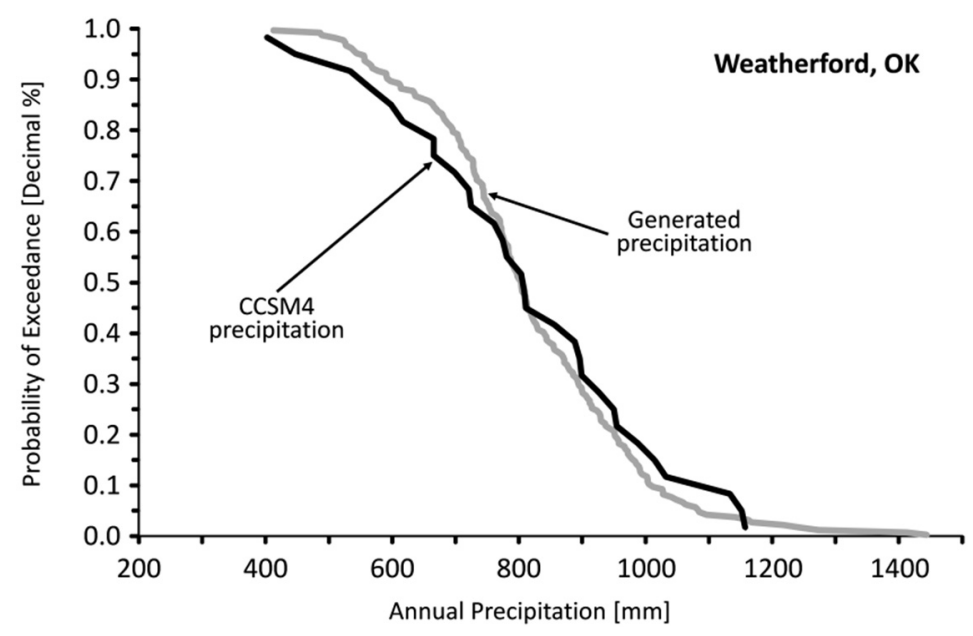

Figure 12. Probability-of-Exceedance of the "CCSM4" projected (30 years) and SYNTOR generated (200 years) annual precipitation for the time period of 2041-2070 at Weatherford, OK.

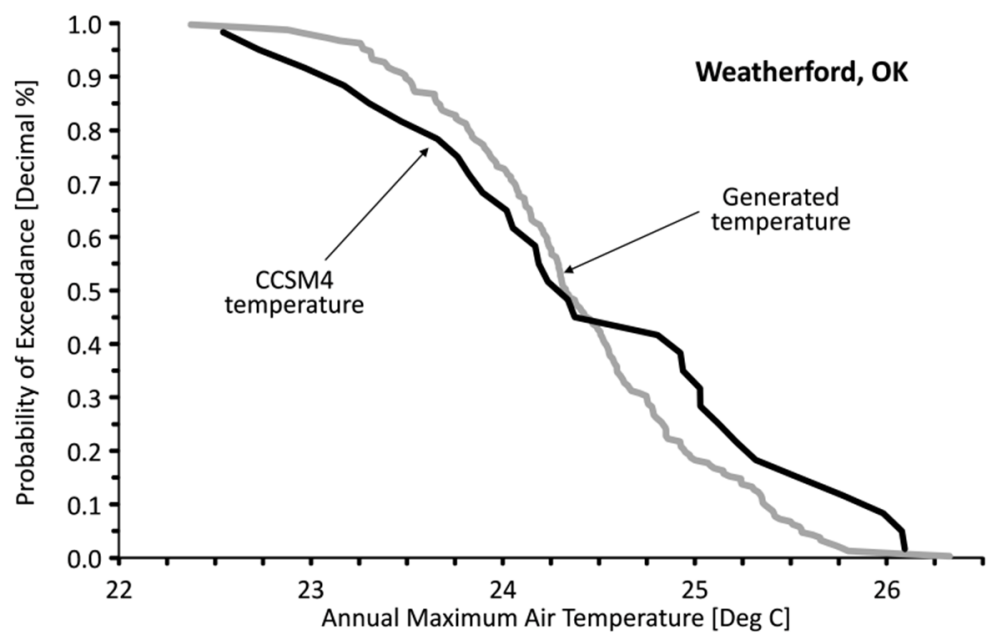

Figure 13. Probability-of-Exceedance of the "CCSM4" projected (30 years) and SYNTOR generated (200 years) annual maximum air temperature for the time period of 2041-2070 at Weatherford, OK. 


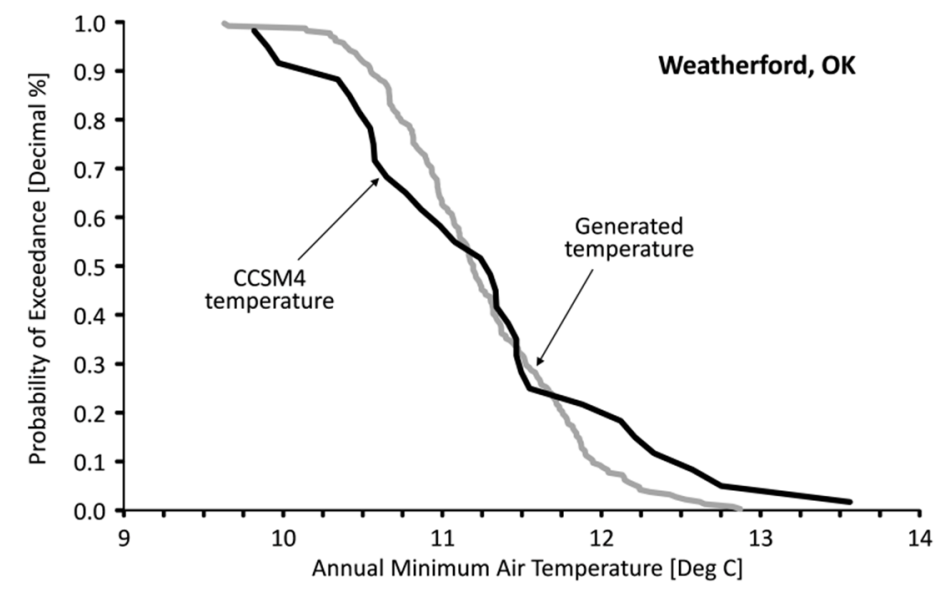

Figure 14. Probability-of-Exceedance of the "CCSM4" projected (30 years) and SYNTOR generated (200 years) annual minimum air temperature for the time period of 2041-2070 at Weatherford, OK.

There are no statistically significant differences in the distribution (Wilcoxon-Mann-Whitney) or mean (Welch's t-test) between the CCSM4-projected and SYNTOR-generated annual and monthly weather data. This includes both precipitation and air temperature, and at an alpha level of 0.05 .

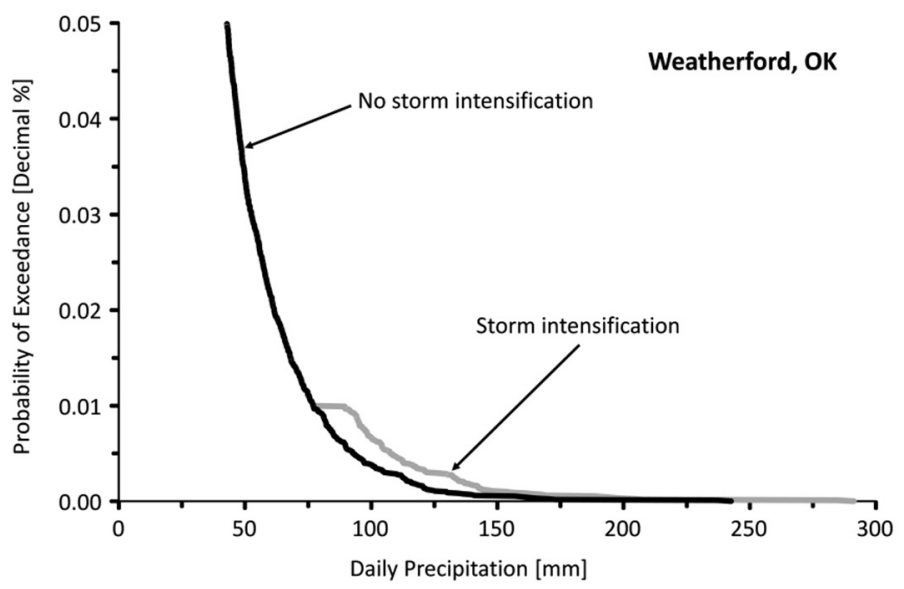

Figure 15. Probability-of-Exceedance (upper 95 percentile only) of the SYNTOR generated (200 years) daily precipitation with and without storm intensification for the time period of 2041-2070 at Weatherford, OK.

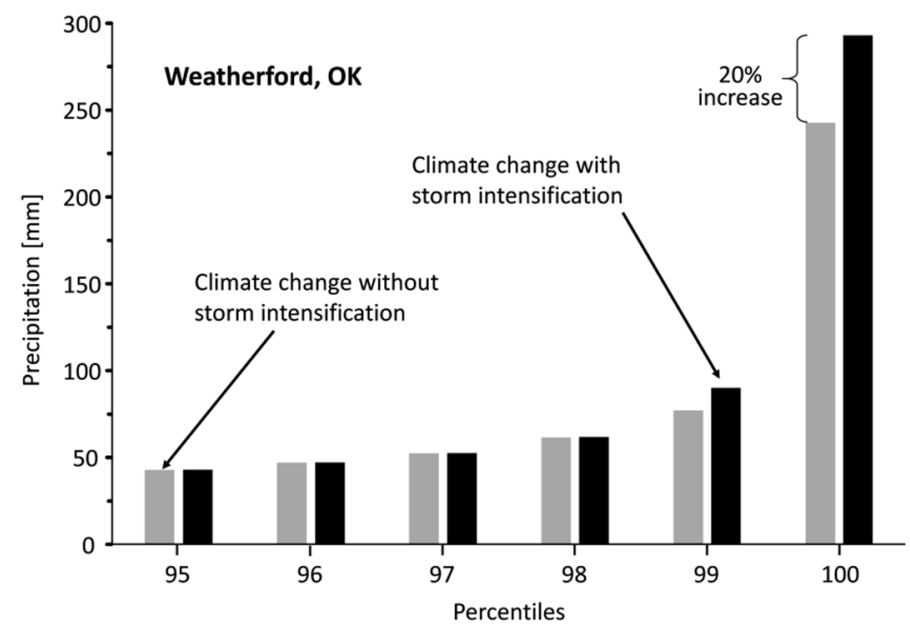

Figure 16. Upper 95 percentile of the SYNTOR generated (200 years) daily precipitation with and without storm intensification for the time period of 2041-2070 at Weatherford, OK. 


\subsubsection{Generation of Synthetic Precipitation for Extreme Storm Intensification}

Intensification of extreme daily storm events is defined as an increase in daily precipitation within the 90-100 percentile category of the daily precipitation distribution. Storm intensification for the region that includes Weatherford, Oklahoma, was estimated to be $16 \%$ of the highest $1 \%$ of all daily events (ICCP, 2014).

Storm intensification for the three percentile categories of heavy (99-99.7\%), very heavy $(99.7-99.9 \%)$, and extreme (99.9 and above) precipitation were $16 \%, 18 \%$, and $20 \%$, respectively. The SYNTOR-generated daily precipitation shows a noticeable jump in the distribution curve after the $99^{\text {th }}$ percentile $(16-20 \%)$ when compared with the generated daily precipitation without storm intensification (Figures 15-16). There is a slight difference of $1.4 \%$ between the CCSM4-projected and SYNTOR-generated annual precipitation. This difference is the result of added precipitation of the intensification model (Table 3). The difference was not statistically significant at an alpha level of 0.05 .

Overall, the model of intensification of extreme precipitation reproduces characteristics that one would expect for the given precipitation intensification parameters.

\section{Conclusions}

SYNTOR is a software product that has the capability of generating long records of synthetic daily precipitation, minimum and maximum air temperature, and solar radiation. These are the main weather variables that drive a hydrologic system and in turn many environmental, agricultural production, and soil and water conservation models. When coupled with a monthly GCM climate projection, SYNTOR can downscale monthly climate change scenarios into representative daily and field-scale weather realizations, including intensification of extreme storm events.

An example application of the weather generation capabilities of SYNTOR was presented for the semi-arid climate conditions of west-central Oklahoma. An evaluation of generated synthetic daily weather for climate change was found to produce monthly summary statistics that were consistent with those of historical observation and climate change scenarios. Based on these findings, it was concluded that SYNTOR is suited to generate representative daily precipitation and air temperature sequences for baseline and climate change conditions.

The merits of this proof-of-concept study extend beyond the specific example presented for west-central Oklahoma. In many instances, agricultural producers require reliable weather information at daily time scales to make critical decisions about crop planting and rotations, livestock grazing, and prescribed burning, among other management tools. The ability of the SYNTOR model to generate such information, under varying and user-defined climate change projection scenarios, provides both land managers and extension professionals with a tool to better ascertain risks and opportunities to production systems. Further exploration of the value of generated weather alternatives is recommended to establish the magnitude and increased risk of agricultural production targets and soil erosion thresholds due to climate change and extreme storm intensification.

\section{Acknowledgments}

We acknowledge the World Climate Research Programme's Working Group on Coupled Modelling, which is responsible for CMIP, and we thank the climate modelling groups for producing and making available their model output. For CMIP, the U.S. Department of Energy's Program for Climate Model Diagnosis and Intercomparison provides coordinating support and led development of software infrastructure in partnership with the Global Organization for Earth System Science Portals.

\section{Conflict of interests}

The authors declare that there is no conflict of interests regarding the publication of this paper.

\section{References}

Baigorra, G. A., Jones, J. W., \& O'Brien, J. J. (2008). Potential predictability of crop yield using an ensemble climate forecast by a regional circulation model.

Garbrecht, J. D., \& Zhang, X. C. (2014). Generating synthetic daily precipitation realizations for seasonal precipitation forecasts. Journal of Hydrologic Engineering, 19(1), 252-264.

Garbrecht, J. D., Zhang, X. J., Schneider, J. M., \& Steiner, J. L. (2010). Utility of seasonal climate forecasts in management of winter-wheat grazing. Applied Engineering in Agriculture, 26(5), 855-866. 
Groisman, P. Y., Knight, R. W., \& Karl, T. R. (2001). Heavy precipitation and high streamflow in the contiguous United States: Trends in the twentieth century. Bulletin of the American Meteorological Society, 82(2), 219-246.

Groisman, P. Y., Knight, R. W., Easterling, D. R., Karl, T. R., Hegerl, G. C., \& Razuvaev, V. N. (2005). Trends in intense precipitation the climate record. Journal of Climate, American Meteorological Society, 18, 1326-1350.

Hosking, J. R. M., \& Wallis, J. R. (1993). Some statistics useful in regional frequency analysis. Water Resour. Res., 29(2), 271-281.

IPCC. (2013). Summary for Policymakers. In T. F. Stocker, D. Qin, G. K. Plattner, M. Tignor, S. K. Allen, J. Boschung, A. Nauels, Y. Xia, V. Bex, \& P. M. Midgley (Eds.), Climate Change 2013: The Physical Science Basis. Contribution of Working Group 1 to the Fifth Assessment Report of the Intergovernmental Panel on Climate Change. Cambridge University Press, Cambridge, United Kingdom and New York, NY, USA.

IPCC. (2014). Climate Change 2014: Synthesis Report (p. 151). Contribution of Working Groups I, II, III to the Fifth Assessment Report of the Intergovernmental Panel on Climate Change. IPCC, Geneva, Switzerland.

Johnson, R. H., Ciesielski, P. E., \& Hart, K. A. (1996). Tropical inversions near the 0C level. J. Atmos. Sci., 53, 1838-1855.

Joshi, S., Garbrecht, J., Brown, D., \& Zhang, J. (2019). Observed Spatiotemporal Trends in Intense Precipitation Events across United States: Applications for Stochastic Weather Generation. Submitted to Climate Change.

Karl, T. R., Melillo, J. M., \& Peterson, T. C. (Eds.) (2009). Global Climate Change Impacts in the United States (p. 188). Cambridge University Press. Retrieved from http://www.globalchange.gov/usimpacts

Kunkel, K. E., Andsager, K., \& Easterling, D. R. (1999). Long-term trends in extreme precipitation events over the conterminous United States and Canada. Journal of Climate, 12, 2515-2527.

Kunkel, K. E., Easterling, D. R., Redmond, K., \& Hubbard, K. (2003). Temporal variation of extreme precipitation events in the United States: 1895-2000. Geophysical Research Letters, 30(17), 1900.

Meinke, H., Sivakumar, M. V. K., Motha, R. P., \& Nelson, R. (2007). Preface: Climate predictions for better agricultural risk management. Aust JAgric Res., 58, 935-938.

Nearing, M. A., Jetten, V., Baffaut, C., Cerdan, O., ..., \& van Oost, K. (2005). Modeling response of soil erosion and runoff to changes in precipitation and cover. Catena, 61(2-3), 131-154.

Nicks, A. D., \& Gander, G. A. (1994). CLIGEN: A weather generator for climate inputs to water resource and other models (pp. 3-94). Preprints, 5th International Conference on Computers in Agriculture, ASAE, St. Joseph, MI.

Nicks, A. D., Lane, L. J., \& Gander, G. A. (1995). Weather generator. In D. C. Flanagan \& M. A. Nearing (Eds.), Chapter 2 in USDA-Water Erosion Prediction Project: Hillslope Profile and Watershed Model Documentation. NSERL Report N0. 10. West Lafayette, Ind.: USDA-ARS National Soil Erosion Research Laboratory.

Reclamation. (2013). Downscaled CMIP3 and CMIP5 climate projections: Release of downscaled CMIP5 climate projections, comparison with preceding information, and summary of user needs (p. 116). U.S. Department of the Interior, Bureau of Reclamation, Technical Service Center, Denver, Colorado. Retrieved from http://gdo-dcp.ucllnl.org/downscaled_cmip_projections/techmemo/downscaled_climate.pdf; https://gdo-dcp.ucllnl.org/downscaled_cmip_projections/dcpInterface.html\#About

Richardson, C. W. (1982). Statistical analysis of rainfall and runoff. Proceedings of the International Symposium on Rainfall-Runoff Modeling, May 18-21, 1981 at Mississippi State University, Mississippi State, Mississippi, USA.

Richardson, C. W. (1985). Weather simulation for crop management models. Transactions of the ASAE, 28(5), 1602-1606.

Richardson, C. W. (2000). Data requirements for estimation of weather generation parameters. Transactions of the ASAE, 43(4), 877-882.

Richardson, C., \& White, D. A. (1984). WGEN: A model for generating daily weather variables. U.S. Department of Agriculture. Agricultural Research Service, Publ. ARS, 8, 38. 
Soltani, A., \& Hoogenboom, G. (2003). Minimum data requirement for parameter estimation of stochastic weather generators. Climate Research, 25, 109-119.

Walsh, J., Wuebbles, D., Hayhoe, K., Kossin, J., ..., \& Somerville, R. (2014). Chapter 2: Our changing climate. Climate change impacts in the United States: The third National Climate Assessment. In J. M. Melillo, T. C. Richmond, \& G. W. Yohe (Eds.), U.S. Global Change Research Program (pp. 19-67).

Waymire, E., \& Gupta, V. K. (1981). The mathematical structure of rainfall representations: Some applications of the point process theory to rainfall processes. Water Resources Research, 17(5), 1287-1294.

Wilks, D. S. (1989). Conditioning stochastic daily precipitation models on total monthly precipitation. Water Resources Research, 25, 1429-1439.

Wilks, D. S., \& Murphy, A. H. (1985). The value of seasonal precipitation forecasts in a haying/ pasturing problem in Western Oregon. Mon. Weather Rev., 113, 173-1745.

Wilks, D. S., \& Murphy, A. H. (1986). A decision-analytic study of the joint value of seasonal precipitation and temperature forecasts in a choice- of $^{-}$crop problem. Atmosphere-ocean, 24(4), 353-368.

Zhang, X. C. (2007). A comparison of explicit and implicit spatial downscaling of GCM output for soil erosion and crop production assessments. Climatic Change, 84, 337-363.

Zhang, X. C., \& Garbrecht, J. D. (2003). Evaluation of CLIGEN precipitation parameters and their implication on WEPP runoff and soil loss prediction. Transactions of the ASAE, 46(2), 311-320.

\section{Copyrights}

Copyright for this article is retained by the author(s), with first publication rights granted to the journal.

This is an open-access article distributed under the terms and conditions of the Creative Commons Attribution license (http://creativecommons.org/licenses/by/4.0/). 